\title{
Genome-wide association studies for diabetic macular edema and proliferative diabetic retinopathy
}

Patricia S. Graham', Georgia Kaidonis², Sotoodeh Abhary², Mark C. Gillies ${ }^{3}$, Mark Daniell', Rohan W. Essex ${ }^{5}$, John H. Chang ${ }^{6,7}$, Stewart R. Lake², Bishwanath Pal ${ }^{7}$, Alicia J. Jenkins ${ }^{8,9}$, Alex W. Hewitt ${ }^{1,10}$, Ecosse L. Lamoureux ${ }^{10,11}$, Philip G. Hykin ${ }^{7}$, Nikolai Petrovsky ${ }^{12}$, Matthew A. Brown ${ }^{13}$, Jamie E. Craig ${ }^{2}$ and Kathryn P. Burdon ${ }^{1,2^{*}}$ (D)

\begin{abstract}
Background: Diabetic macular edema (DME) and proliferative diabetic retinopathy (PDR) are sight-threatening complications of diabetes mellitus and leading causes of adult-onset blindness worldwide. Genetic risk factors for diabetic retinopathy (DR) have been described previously, but have been difficult to replicate between studies, which have often used composite phenotypes and been conducted in different populations. This study aims to identify genetic risk factors for DME and PDR as separate complications in Australians of European descent with type 2 diabetes.
\end{abstract}

Methods: Caucasian Australians with type 2 diabetes were evaluated in a genome-wide association study (GWAS) to compare 270 DME cases and 176 PDR cases with 435 non-retinopathy controls. All participants were genotyped by SNP array and after data cleaning, cases were compared to controls using logistic regression adjusting for relevant covariates.

Results: The top ranked SNP for DME was rs $1990145\left(p=4.10 \times 10^{-6}, \mathrm{OR}=2.0295 \% \mathrm{Cl}[1.50,2.72]\right)$ on chromosome 2. The top-ranked SNP for PDR was rs918519 ( $\left.p=3.87 \times 10^{-6}, \mathrm{OR}=0.3595 \% \mathrm{Cl}[0.22,0.54]\right)$ on chromosome 5. A trend towards association was also detected at two SNPs reported in the only other reported GWAS of DR in Caucasians; rs12267418 near MALRD1 $(p=0.008)$ in the DME cohort and rs16999051 in the diabetes gene PCSK2 $(p=0.007)$ in the PDR cohort.

Conclusion: This study has identified loci of interest for DME and PDR, two common ocular complications of diabetes. These findings require replication in other Caucasian cohorts with type 2 diabetes and larger cohorts will be required to identify genetic loci with statistical confidence. There is considerable overlap in the patient cohorts with each retinopathy subtype, complicating the search for genes that contribute to PDR and DME biology.

Keywords: Genome-wide association study, Diabetic retinopathy, Macular edema, Genetics, Diabetes complications

\section{Background}

Diabetic retinopathy (DR) is a common and potentially blinding complication of both type 1 and type 2 diabetes mellitus. The disease affects multiple vascular and neural cell types of the retina and is the leading cause of new cases of blindness in working aged adults [1]. The early

\footnotetext{
*Correspondence: Kathryn.Burdon@utas.edu.au

${ }^{1}$ Menzies Institute for Medical Research, University of Tasmania, Hobart, Tasmania, Australia

${ }^{2}$ Department of Ophthalmology, Flinders University, Flinders Medical Centre, Adelaide, South Australia, Australia

Full list of author information is available at the end of the article
}

non-proliferative DR (NPDR) stages are characterized by retinal microaneurysms, lipid and protein deposits and cotton wool spots due to damage to retinal vasculature. The later stage, characterised by neovascularisation of the retina is called proliferative DR (PDR). Patients may also develop diabetic macular edema (DME) characterized by build-up of fluid in and beneath the macula, affecting detailed central vision, with or without PDR or NPDR. The prevalence of any retinopathy among patients with diabetes is $40.3 \%$, with a prevalence of $8.2 \%$

(c) The Author(s). 2018 Open Access This article is distributed under the terms of the Creative Commons Attribution 4.0 International License (http://creativecommons.org/licenses/by/4.0/), which permits unrestricted use, distribution, and reproduction in any medium, provided you give appropriate credit to the original author(s) and the source, provide a link to the Creative Commons license, and indicate if changes were made. The Creative Commons Public Domain Dedication waiver (http://creativecommons.org/publicdomain/zero/1.0/) applies to the data made available in this article, unless otherwise stated. 
for sight threatening DR, classified as severe NPDR, PDR or DME [2].

Longer duration of diabetes, poor glycemic control, hypertension, dyslipidemia, central obesity, smoking and high blood pressure are well-documented risk factors for ocular diabetic complications [3, 4]. Genetic factors, however, also play an important role. Family studies have shown that siblings have a greater chance of developing $\mathrm{DR}$, irrespective of other risk factors and the heritable component of DR has been calculated in the range of $25-50 \%[5,6]$. Candidate gene studies have identified numerous genetic variants that may contribute to risk, but have often been inconsistent [7, 8]. Genome-wide association studies (GWAS) are an efficient method to search for genetic variants associated with complex diseases, including DR.

Six GWAS for DR related phenotypes have been reported to date. The first was conducted in MexicanAmericans with type 2 diabetes with severe NDPR or PDR [9]. Subsequent studies in Taiwanese [10] and Japanese [11] participants used a similar disease definition whereas a study in Chinese patients was limited to PDR [12]. The most recent study in type 2 diabetes used a composite definition of blinding DR which included patients with severe NPDR, PDR or DME [13] and was conducted in Caucasian participants for the first time. Only one GWAS for DR has been reported in patients with type 1 diabetes [14]. This study was also conducted in a Caucasian cohort and included patients with DME and PDR as cases. Although many loci have been suggested through these studies, there has been limited success in replicating findings between studies, partly due to small study sizes increasing the likelihood of false positive findings and partly due to different ethnic groups and disease definitions under investigation.

Previous GWAS in Caucasian cohorts have, to date, only considered composite phenotypes. This may limit the results by creating heterogeneous groups with different underlying genetic risk factors. Therefore, we undertook a re-analysis of our previously reported GWAS in Australians with type 2 diabetes [13] stratified by patients with PDR and those with DME, separately. We then compared our findings to those reported in the only other published DR GWAS of Caucasian patients, reported by Grassi et al. [14].

\section{Methods}

Recruitment of participants and clinical data collection

In South Australia, ethics approval was obtained from the Southern Adelaide Health Service Flinders University Clinical Research Ethics Committee (Flinders Medical Centre and Repatriation General Hospital), and the Human Research Ethics Committees (HREC) of the Royal Adelaide Hospital and Queen Elizabeth Hospital.
In New South Wales and Victoria, the HREC of Southeastern Sydney and Illawara Northern Hospital Network (Sydney Eye Hospital), and the HREC of Melbourne Health (Royal Melbourne Hospital) approved this study. The ACT Health HREC approved this study in the Australian Capital Territory. This retrospective, cross sectional study adhered to the tenets of the Declaration of Helsinki. Written informed consent was obtained from all study participants, who have been previously described [13, 15]. Briefly, patients with medically treated type 2 diabetes for at least 5-years were recruited and underwent a thorough ophthalmological examination. DR and DME was graded on clinical examination according to recognised severity scales based on ETDRS criteria [16]. Participants completed a detailed questionnaire and concurrent clinical measurements for blood pressure, renal function and $\mathrm{HbA1c}$ were obtained. $\mathrm{Pa}$ tients were classified as controls if they had no sign of DR or DME. Cases were defined as those with PDR and those with DME present in their worst affected eye, to be analyzed as two separate case cohorts. Patients with mild, moderate or severe NPDR were excluded from the current analysis although some patients with DME had NPDR concurrently. Those with both DME and PDR were included in both case cohorts.

\section{SNP genotyping and data analysis}

Genotyping of single nucleotide polymorphisms (SNPs) across the whole genome have been previously described [13]. Briefly, genomic DNA extracted from whole blood from each individual was genotyped on the OmniExpress SNP array (Illumina). Standard quality control filters were applied to the genotype data and 617,130 SNPs were included in the subsequent analyses. Principal components analysis was conducted using Eigenstrat [17] and individuals falling greater than six standard deviations from the mean of each vector were removed. Q-Q and Manhattan plots were generated using the qqman package [18] in R (https://www.r-project.org/).

Demographic and clinical characteristics were compared using t-tests for continuous traits and chi-squared tests for dichotomous traits. Association of each SNP passing quality control with each DR phenotype (DME and PDR) was assessed using logistic regression adjusted for the covariates age, diabetes duration, sex, hypertension, nephropathy, HbA1c and the first three principal components, using PLINK [19]. $P$-values $<5 \times 10^{-8}$ were deemed to be significant at a genome-wide level. SNPs for comparison with other Caucasian GWAS were chosen from Grassi et al., 2011 [14]. For reported SNPs that were not directly genotyped in the current study, a proxy SNP with $\mathrm{r}^{2}>0.8$ with the reported SNP in HapMap was chosen as described previously [13]. Where no such SNP was available, the SNP with the 
smallest $p$-value within $50 \mathrm{~kb}$ from the reported SNP was selected. When assessing the eight previously reported loci a p-value $<0.0063$ was considered significant under a Bonferroni correction for eight independent tests.

\section{Results}

The DR phenotypes of all participants are shown in Table 1. The PDR cohort consisted of 176 cases (with or without DME) while the DME cohort had 270 cases (with or without PDR). 93 participants had both DME and PDR and were common to both case cohorts. The controls with no PDR or DME were also common to both groups.

The demographics and clinical characteristics of both cases compared to controls are shown in Table 2. Well known DR risk factors including; duration of diabetes, hypertension, nephropathy and HbA1c were significantly different between the control and case groups in both cohorts. Age and sex were associated with PDR with cases being younger and more likely to be male than controls, but this association was not seen with DME.

The effects of population stratification were assessed through visualisation of the Q-Q plots (Fig. 1a and b) and lambda values $\left(\lambda=0.981, \lambda_{1000}=0.943\right.$ for DME; $\lambda=$ $1.001, \lambda_{1000}=1.004$ for PDR) and determined to be negligible following adjustment for the first three principal components. The Manhattan plots (Fig. 1c and d) show the association results for both DME and PDR analyses.

Association results for DME (Additional file 1) and PDR (Additional file 2) showed 7 variants reaching suggestive significance (Table 3). None of the SNPs reached genome-wide significance $\left(p<5 \times 10^{-8}\right)$. In the DME analysis, only two SNPs displayed $p$-values $<1.0 \times 10^{-5}$. The highest ranked SNP was $\operatorname{rs} 1990145\left(p=4.10 \times 10^{-6}\right.$, $\mathrm{OR}=2.0295 \% \mathrm{CI}[1.50,2.72])$ located in an intron of the MRPL19 gene on chromosome 2. The second SNP, rs4771506 $\left(p=6.94 \times 10^{-6}, \mathrm{OR}=1.97[1.46,2.64]\right)$, is on chromosome 13 near the LINC00343 gene. In the PDR analysis the top ranked SNP, rs918519 $\left(p=3.87 \times 10^{-6}\right.$, $\mathrm{OR}=0.35[0.22,0.54])$ and the fifth ranked SNP, rs918520 $\left(p=6.66 \times 10^{-6}, \mathrm{OR}=0.34[0.21,0.54]\right)$ on chromosome 5 , are near the long non-coding RNA gene LOC285626 while the closest protein coding gene is

Table 1 Retinopathy grading of study cohorts. All participants had type 2 diabetes

\begin{tabular}{lc}
\hline Retinopathy grading & $\mathrm{N}$ \\
\hline No retinopathy (controls) & 435 \\
DME only & 177 \\
PDR only & 83 \\
DME and PDR & 93
\end{tabular}

DME diabetic macular edema, PDR proliferative diabetic retinopathy, $N$ number of participants
Table 2 Demographics and clinical characteristics of DME and PDR cases and comparison to controls

\begin{tabular}{llllll}
\hline & Controls & DME Cases & $P$ & PDR Cases & $P$ \\
\hline Number & 435 & 270 & & 176 & \\
Age (yrs) & $66.5 \pm 12.6$ & $65.9 \pm 10.6$ & 0.491 & $62.7 \pm 10.6$ & $<0.001$ \\
Duration (yrs) & $12.6 \pm 7.1$ & $19.2 \pm 8.8$ & $<0.001$ & $19.1 \pm 8.9$ & $<0.001$ \\
Female & $48.5 \%$ & $43.0 \%$ & 0.151 & $35.2 \%$ & 0.003 \\
Hypertension & $76.8 \%$ & $88.1 \%$ & $<0.001$ & $87.5 \%$ & 0.003 \\
Nephropathy & $12.2 \%$ & $24.4 \%$ & $<0.001$ & $29.5 \%$ & $<0.001$ \\
HbA1c (\%) & $7.5 \pm 1.5$ & $8.8 \pm 1.8$ & $<0.001$ & $8.9 \pm 1.9$ & $<0.001$
\end{tabular}

For continuous variables, values are given as the mean \pm standard deviation. For dichotomous variables, values are given as a \%. HbA1c is a \% of total haemoglobin. Duration $=$ known duration of type 2 diabetes in years

IL12B. Three SNPs near the NRXN3 gene on chromosome 14 are also suggestive of association with PDR.

We compared our results to the only other published GWAS of DR in Caucasians. SNPs associated with sightthreatening DR in the type 1 diabetes cohorts reported by Grassi et al. (2011) [14] were evaluated in the DME and PDR datasets. Although none of the SNPs reached formal statistical significance for the eight loci tested at $p<0.006$, two SNPs showed a strong trend towards association with $p \leq 0.008$ (Table 4). The chromosome 10 SNP rs12267418 near MALRD1, was associated with DME, but clearly not with PDR. Further, the chromosome 20 proxy SNP rs16999051 within PCSK2 was associated with $\operatorname{PDR}(p=0.007)$ and was also nominally associated with DME $(p=0.038)$. Both these associations are in the same direction as in the original report.

\section{Discussion}

These GWAS analysed DME and PDR as separate phenotypes of the previously reported sight-threatening DR phenotype of Burdon et al. (2015) [13]. This is the first reported GWAS of DME in any ethnic group. Although no SNPs reached genome wide statistical significance, several suggestive loci have been identified for future investigation in other cohorts with DME phenotyping. The top ranked SNP for DME, rs1990145 is within the second intron of the mitochondrial ribosomal protein L19 (MRPL19). Although there have been no reports on this gene's involvement with diabetic retinopathy, it is expressed in the retina (The Ocular Tissue Database [20]). Evidence suggests a key role for mitochondrial dysfunction in age-related macular degeneration [21]. Polymorphisms in this gene may result in mitochondrial dysfunction and associated eye pathology, with underlying subclinical phenotypes unmasked by conditions of stress such as diabetes and hyperglycaemia. At least three other MRP genes; MRPL9, MRPL23, and MRPL39 map to genomic regions associated with retinitis 

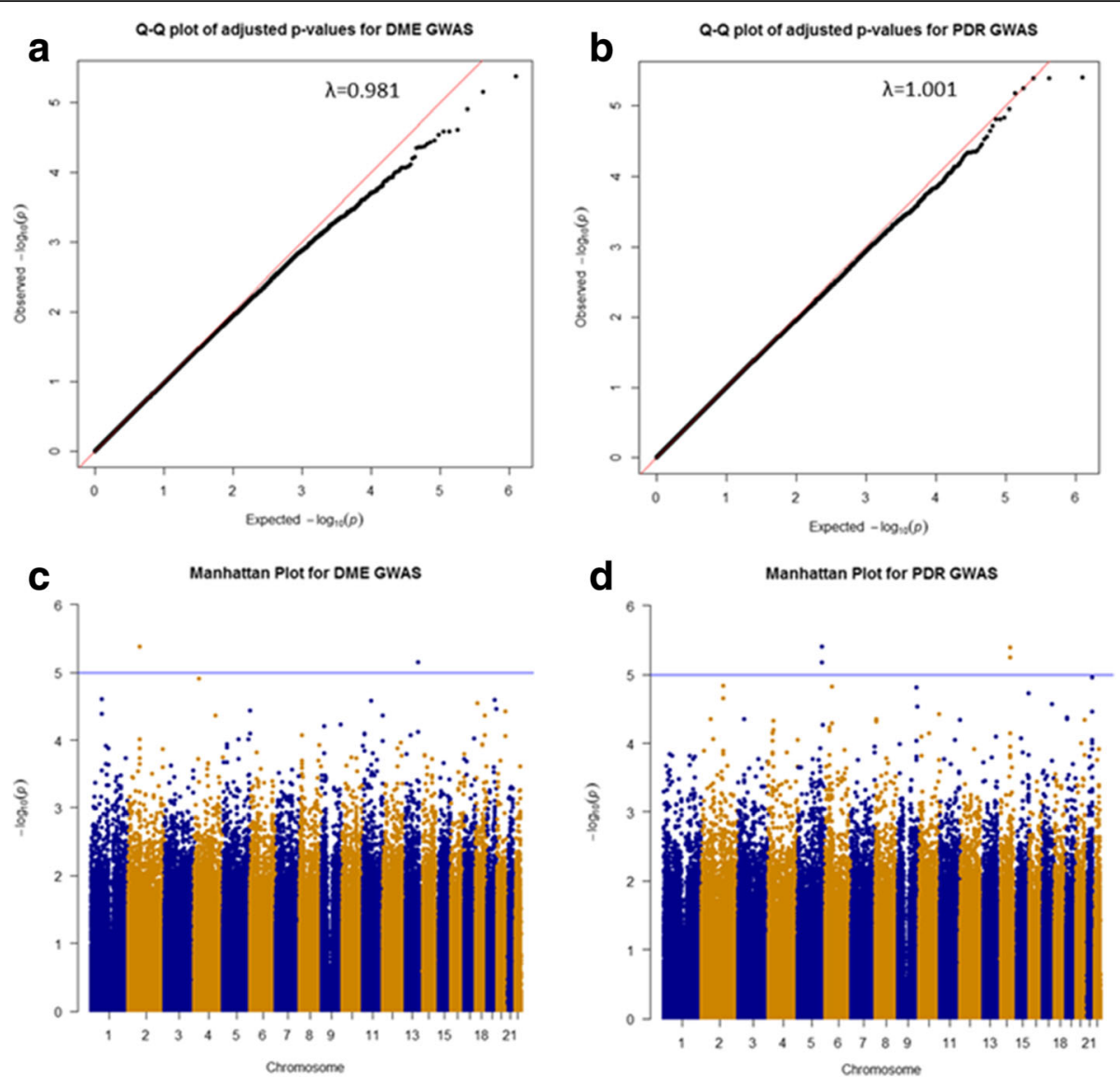

Fig. 1 Q-Q plots and Manhattan plots for DME and PDR GWAS. Q-Q plots for (a) Diabetic Macular Edema and (b) Proliferative Diabetic Retinopathy GWAS. Manhattan plots for (c) Diabetic Macular Edema and (d) Proliferative Diabetic Retinopathy GWAS. The blue horizontal line represents suggestive association at $p=1.0 \times 10^{-5}$

pigmentosa [22] indicating the importance of this pathway in retinal pathology. The second ranked DME SNP, rs4771506, is approximately $80 \mathrm{~kb}$ from the long intergenic non-protein coding RNA 343 (LINC00343). The nearest protein coding gene is $D A O A$, D-amino acid oxidase activator, approximately $350 \mathrm{~kb}$ upstream from the SNP. It is difficult to hypothesise a functional role for this SNP or the nearest genes in DME and replication of these findings is clearly required.
This study is the first GWAS of PDR in Caucasians. We identified suggestive association of two SNPs within LOC285626 and three SNPs within NRXN3 with PDR. The presence of multiple SNPs at each locus with similar statistical evidence provides confidence in the findings, although, as for DME, replication and larger studies are clearly needed. LOC285626 is approximately $35 \mathrm{~kb}$ upstream of the two chromosome 5 SNPs and encodes an uncharacterised, long non-coding RNA. The

Table 3 Top ranked SNPs associated with DME and PDR. SNPs with $p<1.0 \times 10^{-5}$ for each phenotype are shown

\begin{tabular}{|c|c|c|c|c|c|c|c|c|c|}
\hline Phenotype & Chr & SNP & Position in hg 38 (bp) & Minor allele & MAF cases & MAF controls & OR $(95 \% \mathrm{Cl})$ & $P$ & Nearest gene \\
\hline \multirow[t]{2}{*}{$\overline{\mathrm{DME}}$} & 2 & rs1990145 & $75,650,524$ & A & 0.364 & 0.268 & $2.02(1.50,2.72)$ & $4.10 \times 10^{-6}$ & MRPL19 \\
\hline & 13 & rs4771506 & $105,843,651$ & C & 0.325 & 0.263 & $1.97(1.46,2.64)$ & $6.94 \times 10^{-6}$ & LINC00343 \\
\hline \multirow[t]{5}{*}{ PDR } & 5 & rs918519 & $159,399,349$ & T & 0.163 & 0.231 & $0.35(0.22,0.54)$ & $3.87 \times 10^{-6}$ & LOC285626 \\
\hline & 14 & rs1158314 & $79,961,389$ & G & 0.515 & 0.400 & $2.16(1.56,3.00)$ & $4.01 \times 10^{-6}$ & NRXN3 \\
\hline & 14 & rs8004963 & $79,958,817$ & C & 0.515 & 0.400 & $2.16(1.56,3.00)$ & $4.01 \times 10^{-6}$ & NRXN3 \\
\hline & 14 & rs11159428 & $79,950,890$ & $\mathrm{~T}$ & 0.512 & 0.399 & $2.13(1.54,2.95)$ & $5.63 \times 10^{-6}$ & NRXN3 \\
\hline & 5 & rs918520 & $159,399,302$ & C & 0.131 & 0.211 & $0.34(0.21,0.54)$ & $6.66 \times 10^{-6}$ & LOC285626 \\
\hline
\end{tabular}

Odds ratios (OR) calculated with respect to the minor allele. $P$ values are adjusted for age, duration of diabetes, sex, hypertension, nephropathy (defined as microalbuminuria or worse), HbA1c and the first 3 principal components. Chr chromosome, MAF minor allele frequency 
Table 4 Comparison of GWAS findings for DME and PDR with a previously published GWAS for sight-threatening DR in a Caucasian population (Grassi et al., 2011 [14])

\begin{tabular}{|c|c|c|c|c|c|c|c|c|c|c|c|c|}
\hline \multirow{3}{*}{ Chr } & \multicolumn{5}{|c|}{ Published in Grassi et al (2011) } & \multicolumn{7}{|c|}{ This Study } \\
\hline & \multirow{2}{*}{ SNP } & \multirow{2}{*}{$\begin{array}{l}\text { Position in } \\
\text { hg38 (bp) }\end{array}$} & \multirow{2}{*}{ Gene } & \multirow{2}{*}{$\mathbf{P}$} & \multirow{2}{*}{ OR } & \multirow{2}{*}{ Proxy SNP } & \multirow{2}{*}{$\begin{array}{l}\text { Position in } \\
\text { hg38 (bp) }\end{array}$} & \multirow{2}{*}{$\begin{array}{l}\text { Minor } \\
\text { allele }\end{array}$} & \multicolumn{2}{|c|}{ DME } & \multicolumn{2}{|l|}{ PDR } \\
\hline & & & & & & & & & $\mathbf{P}$ & OR $(0.95 \%$ CI $)$ & $\mathbf{P}$ & OR( $(0.95 \% \mathrm{CI})$ \\
\hline 4 & rs11736136 & 82097121 & - & $6.4 \times 10^{-6}$ & 0.51 & rs 2035912 & 82086322 & C & 0.701 & $0.91(0.55-1.50)$ & 0.731 & $1.10(0.63-1.92)$ \\
\hline 6 & rs227455 & 165064562 & - & $1.6 \times 10^{-7}$ & 0.53 & - & - & $\mathrm{C}$ & 0.662 & $0.91(0.61-1.37)$ & 0.888 & $1.03(0.65-1.65)$ \\
\hline 10 & rs17670074 & 19416454 & MALRD1 $^{a}$ & $8.1 \times 10^{-6}$ & 1.74 & - & - & $\mathrm{C}$ & 0.454 & $0.90(0.69-1.18)$ & 0.793 & $0.96(0.71-1.31)$ \\
\hline 10 & rs12267418 & 19425625 & $M_{A L R D 1^{a}}$ & $8.2 \times 10^{-6}$ & 0.5 & - & - & $\mathrm{A}$ & 0.008 & $0.55(0.35-0.85)$ & 0.529 & $0.86(0.54-1.38)$ \\
\hline 13 & rs238250 & 42340510 & - & $7.7 \times 10^{-6}$ & 1.66 & - & - & $\mathrm{A}$ & 0.483 & $0.86(0.58-1.30)$ & 0.705 & $0.92(0.58-1.44)$ \\
\hline 13 & rs 4941432 & 42524211 & - & $7.9 \times 10^{-6}$ & 1.62 & rs9315921 & 42496635 & G & 0.143 & $1.25(0.93-1.69)$ & 0.169 & $1.28(0.90-1.83)$ \\
\hline 16 & rs151227 & 28538187 & NUPR1 & $3.2 \times 10^{-6}$ & 0.58 & - & - & $\mathrm{T}$ & 0.369 & $0.83(0.55-1.25)$ & 0.778 & $1.07(0.68-1.69)$ \\
\hline 16 & rs 151320 & 28557357 & NPIPB $8^{b}$ & $3.1 \times 10^{-6}$ & 0.58 & - & - & $\mathrm{A}$ & 0.309 & $0.81(0.53-1.22)$ & 0.706 & $1.09(0.69-1.73)$ \\
\hline 16 & rs 151230 & 28571894 & $N P I P B 8^{b}$ & $3.2 \times 10^{-6}$ & 0.58 & - & - & $\mathrm{T}$ & 0.333 & $0.81(0.54-1.23)$ & 0.701 & $1.09(0.69-1.73)$ \\
\hline 16 & rs151229 & 28573616 & $N P I P B 8^{b}$ & $3.2 \times 10^{-6}$ & 0.58 & - & - & $\mathrm{T}$ & 0.370 & $0.83(0.55-1.25)$ & 0.701 & $1.09(0.69-1.73)$ \\
\hline 16 & rs11641853 & 28578398 & $N P I P B 8^{c}$ & $3.4 \times 10^{-6}$ & 0.58 & - & - & $\mathrm{C}$ & 0.366 & $0.83(0.54-1.25)$ & 0.620 & $1.12(0.71-1.78)$ \\
\hline 16 & rs10521145 & 28585563 & NPIPB $8^{c}$ & $3.4 \times 10^{-6}$ & 0.58 & - & - & $\mathrm{T}$ & 0.346 & $0.82(0.54-1.24)$ & 0.649 & $1.11(0.70-1.76)$ \\
\hline 16 & rs17684886 & 75052977 & ZNRF1 & $6.8 \times 10^{-6}$ & 0.56 & rs9936747 & 75069054 & $\mathrm{C}$ & 0.822 & $1.05(0.70-1.57)$ & 0.925 & $1.02(0.64-1.64)$ \\
\hline 17 & rs11871508 ${ }^{d}$ & 18800718 & FAMI8B & $4.8 \times 10^{-6}$ & 0.24 & rs 4630608 & 18775235 & $\mathrm{C}$ & 0.651 & $0.94(0.72-1.23)$ & 0.574 & $0.91(0.67-1.25)$ \\
\hline 20 & rs737141 ${ }^{d}$ & 17349080 & PCSK2 & $7.2 \times 10^{-6}$ & 2.12 & rs16999051 & 17380837 & $\mathrm{~T}$ & 0.038 & $1.62(1.03-2.54)$ & 0.007 & $2.01(1.21-3.35)$ \\
\hline
\end{tabular}

$p<0.006$ was required for significance to account for the eight loci tested (as separated by horizontal bold lines). Nominally significant $p$-values $(p<0.05)$ are shown in bold. Proxy SNPs were used in this study when published SNPs were not available. Proxy SNPs were selected based on $r^{2}$ value with the reported SNP in the CEU population of HapMap. 95\% Cl for the OR was not reported by Grassi et al., 2011 [14])

aln Grassi et al. 2011, the MALRD1 locus was labelled as C10orf112 and NPIPB8 was labelled as CCDC101 ${ }^{\mathrm{b}}$ and SULT1A

${ }^{\mathrm{d}} \mathrm{SNP}$ with lowest $p$-value within $50 \mathrm{~kb}$ of the published SNP (no appropriate proxy SNP identified)

nearest protein coding gene is $I L 12 B$ (Interleukin 12B), a further $33 \mathrm{~kb}$ upstream. $I L 12 B$ is expressed in the retina (The Ocular Tissue Database [20]) and has been implicated in both type $1[23,24]$ and type 2 diabetes [25], although there are no prior reports of a role in diabetic eye disease. NRXN3 (Neurexin 3) is located approximately $90 \mathrm{~kb}$ upstream from the three associated SNPs on chromosome 14 and is strongly expressed in the retina. The gene encodes multiple transcripts and although the exact function of each is unknown, neurexin proteins function as cell adhesion molecules and receptors in neurons. Genetic variants in NRXN3 have been associated with increased waist circumference and obesity [26, 27], which are important risk factors for and features of type 2 diabetes $[28,29]$ and central obesity is a risk factor for DR [30, 31]. NRXN3 polymorphisms are also associated with smoking behaviour [32], which in turn is a risk factor for age-related macular degeneration [33] although the contributory role of smoking to DR is less than for age-related macular degeneration. If NRXN3 is confirmed to be important in PDR, there may be overlapping genetic risk factors for risk of type 2 diabetes and PDR.

None of the highest ranked SNPs in this study have previously been reported in other GWAS of DR [10-12, 14, 34]. All but one of these studies [14] were of nonCaucasian participants. If there is a genetic component to susceptibility which is linked with ethnicity, it could explain the difficulty in replicating results from these other studies. The lack of support for SNPs found in this current study with other published GWAS does not discount their possible association with DR. Replication analyses with larger numbers of participants would provide greater statistical power to confirm their association with PDR and/ or DME. Similarly, molecular manipulation of cultured cell and animal models may be informative.

We have also directly compared the results of our DME and PDR GWAS to the only other DR GWAS of Caucasians [14]. Grassi et al. [14] reported a GWAS of severe DR in type 1 diabetes in Caucasian Americans, defined as PDR or DME. Similar to the current study, no variants were reported at the genome-wide significant level, however, several loci showed suggestive association $\left(p<1 \times 10^{-5}\right)$. One of the top ranked variants, rs12267418, trended towards association with severe DR in the earlier report $\left(p=8.2 \times 10^{-6}\right)$ [14] and with DME in the current study ( $p=0.008,8$ loci tested). This SNP is located within an intron of the MALRD1 gene on chromosome 10. Very little is known about the function of MALRD1 (MAM and LDL receptor class A domain containing 1). Another recent study [35] on DR in a Chinese type 2 diabetic population included two SNPs within the MALRD1 gene, although an association was not found (rs17670074 $p=0.27$, rs9888035 $p=0.30$ ). Further research is needed to understand the possible role of this gene in DR and whether ethnic differences or epigenetic effects might be responsible for the differing results.

We also show nominal association at the chromosome 20 locus near PCSK2 reported by Grassi et al. Due to the use of different SNP arrays in the two studies, we report results for rs16999051 whereas the earlier report 
was for rs737141. The association of this SNP with PDR was very close to significance $(p=0.007)$ and the SNP also reached nominal significance with DME $(p=0.038)$. This may suggest some overlap in the genetic susceptibility to different diabetic ocular complications, but may also be due to the number of DME patients who also have PDR. This SNP is located within an intron of the PCSK2 gene on chromosome 20. The proprotein convertase subtilisin/ kexin-type 2 gene has been well-documented in its link to susceptibility to type 2 diabetes $[36,37]$.

This study compared type 2 diabetes participants with type 1 diabetic participants in Grassi et al. (2011) [14]. The similar trends at several SNPs may suggest that some loci are associated with DR regardless of diabetes type. Similarly, the DR associated SNP found in our original report [13], rs9896052, was found in the discovery type 2 diabetes cohort as well as the replication type 1 diabetes group, again suggesting that at least some DR risk factors are common between types of diabetes.

A strength of this study is the size of the original cohort relative to other DR studies [15], and the detailed clinical evaluation of the participants. Stratifying the sight-threatening phenotype of our earlier study [13] into DME and PDR provided more homogeneous groups for analysis. This study is comparable in size to other published GWAS for DR phenotypes and provides a useful breakdown of data from the previously reported composite phenotype of blinding retinopathy [13], although we have a limited ability to detect small effect sizes. A recognised limitation is that 93 participants have both PDR and DME, indicating that these phenotypes may not be independent even though we have conducted the analyses separately. This issue will affect any cohort of diabetic patients and can only be unravelled using larger cohorts and laboratory based functional testing. It is noteworthy that many participants have either DME or PDR, supporting the hypothesis that different factors lead to these different clinical phenotypes. Further value could be gained from the data by a meta-analysis with other reported studies, following harmonization of phenotypes. Imputation of ungenotyped SNPs may also reveal additional loci, however, most loci detected through imputation are also tagged by directly genotyped SNPs. Such analyses are likely to be of limited value in this small cohort. Replication cohorts are also required to fully evaluate the findings reported herein, particularly as genome-wide statistical significance was not reached. Relevant basic science studies are also merited.

\section{Conclusions}

This is the first GWAS specifically targeting DME and PDR separately as ocular complications of sightthreatening DR. MRPL19 and NRXN3 have been identified as novel loci with suggestive association with DME and PDR respectively. Two long non-coding RNAs of unknown function (LINC00343 and LOC285626) have also been highlighted as possible candidates for these common, blinding complications of diabetes, however, further genetic studies are warranted to confirm these findings. This study has also provided supportive evidence for previously reported loci, PCKS2 and MALRD1 in DR in Caucasians. Despite recent advances in treatment for diabetes related systemic risk factors and of local DME and PDR with anti-VEGF therapies and fenofibrate [38], many patients remain visually impaired. Studies such as this can lead to clearer understanding of important biological pathways relevant to disease and will be important tools in the global fight to prevent blindness from diabetes.

\section{Additional files}

Additional file 1: Association results for Diabetic Macular Edema GWAS. Only SNPs with $p<0.05$ are included in this file. (TXT $21762 \mathrm{~kb}$ )

Additional file 2: Association results for Proliferative Diabetic Retinopathy GWAS. Only SNPs with $p<0.05$ are included in this file. (TXT $21943 \mathrm{~kb}$ )

\begin{abstract}
Abbreviations
Chr: Chromosome; DME: Diabetic macular edema; DR: Diabetic retinopathy; GWAS: Genome-wide association study; MAF: Minor allele frequency; $\mathrm{N}$ : Number of participants; NPDR: Non-proliferative diabetic retinopathy; OR (95\% Cl): Odds ratio (with 95\% confidence intervals); P: P-value, calculated probability; PDR: Proliferative diabetic retinopathy; SNPs: Single nucleotide polymorphisms
\end{abstract}

\section{Acknowledgements}

We thank the following people for technical assistance with patient recruitment, DNA extraction and genotyping: E.Souzeau, K. Dowell, A. Kuot and S. Thorpe (Department of Ophthalmology, Flinders University, Adelaide, SA, Australia), L. Kolmogorova (Save Sight Institute, University of Sydney, Sydney, NSW, Australia), J. Haariko (Ophthalmology, Australian National University, Canberra, ACT, Australia), F. Richter (Department of Ophthalmology, Royal Melbourne Hospital, Melbourne, VIC, Australia) and J. Hadler (Diamantina Institute, The University of Queensland, Brisbane, QLD, Australia).

\section{Funding}

This research was funded by the National Health and Medical Research Council of Australia (GNT 595918). The funding body played no role in the design of the study, data collection, analysis, interpretation or writing of the manuscript.

\section{Availability of data and materials}

The datasets supporting the conclusions of this article are included within the article and its additional files (S1 and S2).

\section{Authors' contributions}

SA, MCG, MD, BP, AWH, ELL, NP, MAB, JEC and KPB contributed to the conceptualization of the study and obtained funding. MCG, MD, RWE, JHC, SRL, BP, AJJ, AWH ELL, PGH, NP and JEC recruited patients and collected clinical data. PSG, GK, SA, MAB and KPB curated the data and performed the analyses. PSG and KPB prepared the original draft and all authors contributed to editing and review and provided intellectual input to the final manuscript. All authors read and approved the final manuscript.

Ethics approval and consent to participate

In South Australia, ethics approval was obtained from the Southern Adelaide Health Service Flinders University Clinical Research Ethics Committee 
(Flinders Medical Centre and Repatriation General Hospital), and the Human Research Ethics Committees (HREC) of the Royal Adelaide Hospital and Queen Elizabeth Hospital. In New South Wales and Victoria, the HREC of Southeastern Sydney and Illawara Northern Hospital Network (Sydney Eye Hospital), and the HREC of Melbourne Health (Royal Melbourne Hospital) approved this study. The ACT Health HREC approved this study in the Australian Capital Territory. The study adhered to the tenets of the Declaration of Helsinki.

\section{Competing interests}

The authors declare that they have no competing interests.

\section{Publisher's Note}

Springer Nature remains neutral with regard to jurisdictional claims in published maps and institutional affiliations.

\section{Author details}

${ }^{1}$ Menzies Institute for Medical Research, University of Tasmania, Hobart, Tasmania, Australia. ${ }^{2}$ Department of Ophthalmology, Flinders University, Flinders Medical Centre, Adelaide, South Australia, Australia. ${ }^{3}$ Save Sight Institute, Clinical Ophthalmology and Eye Health, University of Sydney, Sydney, New South Wales, Australia. ${ }^{4}$ Department of Ophthalmology, Royal Melbourne Hospital, Parkville, Victoria, Australia. ${ }^{5}$ Academic Unit of Ophthalmology, Australian National University, Canberra, Australia. ${ }^{6}$ School of Medical Sciences, University of NSW, Sydney, New South Wales, Australia. ${ }^{7}$ Medical Retina Service, Moorfields Eye Hospital, London, UK. ${ }^{8} \mathrm{NHMRC}$ Clinical Trials Centre, University of Sydney, Camperdown, New South Wales, Australia. ${ }^{9}$ St Vincent's Hospital, Fitzroy, Victoria, Australia. ${ }^{10}$ Centre for Eye Research Australia, University of Melbourne, East Melbourne, Victoria, Australia. ${ }^{11}$ Singapore Eye Research Institute, Singapore, Singapore.

${ }^{12}$ Department of Endocrinology, Flinders University, Flinders Medical Centre, Adelaide, South Australia, Australia. ${ }^{13}$ Institute of Health and Biomedical Innovation, Queensland University of Technology, Brisbane, Australia.

Received: 30 August 2017 Accepted: 19 April 2018

Published online: 08 May 2018

\section{References}

1. National Diabetes Data Group: Diabetes in America: National Institutes of Health, National Institute of Diabetes and Digestive and Kidney Diseases; 1995.

2. Kempen JH, O'Colmain BJ, Leske MC, Haffner SM, Klein R, Moss SE, Taylor HR, Hamman RF. The prevalence of diabetic retinopathy among adults in the United States. Arch Ophthalmol. 2004;122(4):552-63.

3. Tapp RJ, Shaw JE, Harper CA, de Courten MP, Balkau B, McCarty DJ, Taylor HR, Welborn TA, Zimmet PZ, AusDiab Study G. The prevalence of and factors associated with diabetic retinopathy in the Australian population Diabetes Care. 2003;26(6):1731-7.

4. Yau JW, Rogers SL, Kawasaki R, Lamoureux EL, Kowalski JW, Bek T, Chen SJ, Dekker JM, Fletcher A, Grauslund J, et al. Global prevalence and major risk factors of diabetic retinopathy. Diabetes Care. 2012;35(3):556-64.

5. Arar NH, Freedman Bl, Adler SG, lyengar SK, Chew EY, Davis MD, Satko SG, Bowden DW, Duggirala R, Elston RC, et al. Heritability of the severity of diabetic retinopathy: the FIND-eye study. Invest Ophthalmol Vis Sci. 2008; 49(9):3839-45

6. Hietala K, Forsblom C, Summanen P, Groop PH, FinnDiane Study Group. Heritability of proliferative diabetic retinopathy. Diabetes. 2008;57(8):2176-80.

7. Abhary S, Hewitt AW, Burdon KP, Craig JE. A systematic meta-analysis of genetic association studies for diabetic retinopathy. Diabetes. 2009;58(9): 2137-47.

8. Cho H, Sobrin L. Genetics of diabetic retinopathy. Curr Diab Rep. 2014;14(8):515.

9. Fu W, O'Connor TD, Jun G, Kang HM, Abecasis G, Leal SM, Gabriel S, Altshuler D, Shendure J, Nickerson DA, et al. Analysis of 6,515 exomes reveals the recent origin of most human protein-coding variants. Nature. 2013;493(7431):216-20

10. Huang YC, Lin JM, Lin HJ, Chen CC, Chen SY, Tsai CH, Tsai FJ. Genome-wide association study of diabetic retinopathy in a Taiwanese population. Ophthalmology. 2011;118(4):642-8.

11. Awata T, Yamashita H, Kurihara S, Morita-Ohkubo T, Miyashita Y, Katayama S, Mori K, Yoneya S, Kohda M, Okazaki Y, et al. A genome-wide association study for diabetic retinopathy in a Japanese population: potential association with a long intergenic non-coding RNA. PLoS One. 2014;9(11):e111715.
12. Sheu WH, Kuo JZ, Lee IT, Hung YJ, Lee WJ, Tsai HY, Wang JS, Goodarzi MO, Klein R, Klein BE, et al. Genome-wide association study in a Chinese population with diabetic retinopathy. Hum Mol Genet. 2013;22(15):3165-73.

13. Burdon KP, Fogarty RD, Shen W, Abhary S, Kaidonis G, Appukuttan B, Hewitt AW, Sharma S, Daniell M, Essex RW, et al. Genome-wide association study for sight-threatening diabetic retinopathy reveals association with genetic variation near the GRB2 gene. Diabetologia. 2015;58:2288-97.

14. Grassi MA, Tikhomirov A, Ramalingam S, Below JE, Cox NJ, Nicolae DL. Genome-wide meta-analysis for severe diabetic retinopathy. Hum Mol Genet. 2011;20(12):2472-81.

15. Kaidonis G, Abhary S, Daniell M, Gillies M, Fogarty R, Petrovsky N, Jenkins A, Essex R, Chang JH, Pal B, et al. Genetic study of diabetic retinopathy: recruitment methodology and analysis of baseline characteristics. Clin Exp Ophthalmol. 2014;42(5):486-93.

16. Wilkinson CP, Ferris FL 3rd, Klein RE, Lee PP, Agardh CD, Davis M, Dills D, Kampik A, Pararajasegaram R, Verdaguer JT, et al. Proposed international clinical diabetic retinopathy and diabetic macular edema disease severity scales. Ophthalmology. 2003;110(9):1677-82.

17. Price AL, Patterson NJ, Plenge RM, Weinblatt ME, Shadick NA, Reich D. Principal components analysis corrects for stratification in genome-wide association studies. Nat Genet. 2006;38(8):904-9.

18. Turner SD. Qqman: an R package for visualizing GWAS results using Q-Q and Manhattan plots. bioRxiv. 2014;10:005165.

19. Purcell S, Neale B, Todd-Brown K, Thomas L, Ferreira MA, Bender D, Maller J, Sklar P, de Bakker PI, Daly MJ, et al. PLINK: a tool set for whole-genome association and population-based linkage analyses. Am J Hum Genet. 2007; 81(3):559-75.

20. Wagner AH, Anand VN, Wang WH, Chatterton JE, Sun D, Shepard AR,

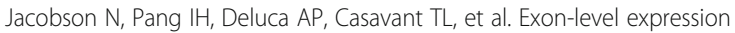
profiling of ocular tissues. Exp Eye Res. 2013;111:105-11.

21. Terluk MR, Kapphahn RJ, Soukup LM, Gong H, Gallardo C, Montezuma SR, Ferrington DA. Investigating mitochondria as a target for treating agerelated macular degeneration. J Neurosci. 2015;35(18):7304-11.

22. Kenmochi N, Suzuki T, Uechi T, Magoori M, Kuniba M, Higa S, Watanabe K, Tanaka T. The human mitochondrial ribosomal protein genes: mapping of 54 genes to the chromosomes and implications for human disorders. Genomics. 2001;77(1):65-70.

23. Li J, Zhang C, Wang JB, Chen SS, Zhang TP, Li S, Pan HF, Ye DQ. Relationship between the IL12B (rs3212227) gene polymorphism and susceptibility to multiple autoimmune diseases: a meta-analysis. Mod Rheumatol. 2016;26(5):749-56.

24. Morahan G, McKinnon E, Berry J, Browning B, Julier C, Pociot F, James I. Evaluation of IL12B as a candidate type I diabetes susceptibility gene using data from the type I diabetes genetics consortium. Genes Immun. 2009;10 Suppl 1:S64-8.

25. Eirís N, González-Lara L, Santos-Juanes J, Queiro R, Coto E, Coto-Segura P. Genetic variation at IL12B, IL23R and IL23A is associated with psoriasis severity, psoriatic arthritis and type 2 diabetes mellitus. J Dermatol Sci. 2014; 75(3):167-72.

26. Heard-Costa NL, Zillikens MC, Monda KL, Johansson A, Harris TB, Fu M, Haritunians T, Feitosa MF, Aspelund T, Eiriksdottir G, et al. NRXN3 is a novel locus for waist circumference: a genome-wide association study from the CHARGE consortium. PLoS Genet. 2009:5(6):e1000539.

27. Bille DS, Banasik K, Justesen JM, Sandholt CH, Sandbaek A, Lauritzen T, Jorgensen T, Witte DR, Holm JC, Hansen T, et al. Implications of central obesity-related variants in LYPLAL1, NRXN3, MSRA, and TFAP2B on quantitative metabolic traits in adult Danes. PLoS One. 2011;6(6):e20640

28. Despres J. Intra-abdominal obesity: an untreated risk factor for type 2 diabetes and cardiovascular disease. J Endocrinol Investig. 2006;29(3):77.

29. Snijder MB, Dekker JM, Visser M, Bouter LM, Stehouwer CD, Kostense PJ, Yudkin JS, Heine RJ, Nijpels G, Seidell JC. Associations of hip and thigh circumferences independent of waist circumference with the incidence of type 2 diabetes: the Hoorn study. Am J Clin Nutr. 2003;77(5):1192-7.

30. Hammes HP, Welp R, Kempe HP, Wagner C, Siegel E, Holl RW. Risk factors for retinopathy and DME in type 2 diabetes-results from the German/ Austrian DPV database. PLoS One. 2015;10(7):e0132492.

31. van Leiden HA, Dekker JM, Moll AC, Nijpels G, Heine RJ, Bouter LM, Stehouwer CD, Polak BC. Blood pressure, lipids, and obesity are associated with retinopathy: the Hoorn study. Diabetes Care. 2002;25(8):1320-5.

32. Docampo E, Ribases M, Gratacos M, Bruguera E, Cabezas C, Sanchez-Mora C, Nieva G, Puente D, Argimon-Pallas JM, Casas M, et al. Association of 
neurexin 3 polymorphisms with smoking behavior. Genes Brain Behav 2012;11(6):704-11.

33. Shim SH, Kim SG, Bae JH, Yu HG, Song SJ. Risk factors for progression of early age-related macular degeneration in Koreans. Ophthalmic Epidemiol. 2016;23(2):80-7.

34. Fu YP, Hallman DM, Gonzalez VH, Klein BE, Klein R, Hayes MG, Cox NJ, Bell Gl, Hanis CL. Identification of diabetic retinopathy genes through a genome-wide association study among Mexican-Americans from Starr County, Texas. J Ophthalmol. 2010;2010. https://doi.org/10.1155/2010/861291.

35. Peng D, Wang J, Zhang R, Jiang F, Tang S, Chen M, Yan J, Sun X, Wang $S$, Wang T, et al. Common variants in or near ZNRF1, COLEC12, SCYL1BP1 and API5 are associated with diabetic retinopathy in Chinese patients with type 2 diabetes. Diabetologia. 2015;58(6):1231-8.

36. Leak TS, Keene KL, Langefeld CD, Gallagher CJ, Mychaleckyj JC, Freedman BI, Bowden DW, Rich SS, Sale MM. Association of the proprotein convertase subtilisin/kexin-type 2 (PCSK2) gene with type 2 diabetes in an African American population. Mol Genet Metab. 2007:92(1-2):145-50.

37. Zheng X, Ren W, Zhang S, Liu J, Li S, Li J, Yang P, He J, Su S, Li P. Association of type 2 diabetes susceptibility genes (TCF7L2, SLC30A8, PCSK1 and PCSK2) and proinsulin conversion in a Chinese population. Mol Biol Rep. 2012;39(1):17-23.

38. Sharma N, Ooi J, Ong J, Newman D. The use of fenofibrate in the management of patients with diabetic retinopathy: an evidence-based review. Aust Fam Physician. 2015:44:367-70.

Ready to submit your research? Choose BMC and benefit from:

- fast, convenient online submission

- thorough peer review by experienced researchers in your field

- rapid publication on acceptance

- support for research data, including large and complex data types

- gold Open Access which fosters wider collaboration and increased citations

- maximum visibility for your research: over $100 \mathrm{M}$ website views per year

At BMC, research is always in progress.

Learn more biomedcentral.com/submissions 